\title{
A case of widespread non-pigmented hair regrowth in diffuse alopecia areata
}

\author{
Younes Barbach, Hanane Baybay, Mohammed Chaouche, Sara Elloudi, Fatima Zahra \\ Mernissi
}

Departement of Dermatology, CHU Hassan II, Fes, CHU Hassan II, Fès, Morocco

Corresponding author: Dr. Younes Barbach, E-mail: dr.younes2011@gmail.com

A discrete area of non-pigmented hair regrowth in patients with localized alopecia areata is a recognized phenomenon [1]. However, widespread non-pigmented hair regrowth in patients with diffuse alopecia areata has rarely been described in the literature.

This whitening appearance is thought to be attributable to two main factors. First, pigmented hairs are preferentially lost, possibly due to the presence of antibodies to melanocytes within pigmented hairs [2]. Exclamation mark hairs serve as a marker for ongoing inflammatory activity in the hair shaft and subsequent alopecia. In alopecia areata, these hairs are usually pigmented, further confirming the selectivity of disease activity. In addition, in areas of hair regrowth, reduced numbers of melanoblasts and abnormal melanogenesis have been demonstrated $[3,4]$.

We report a case of a 20-year-old woman, with no past history suggestive of alopecia areata, and no past or family history of autoimmune disease. In particular, screening thyroid function tests were normal.

At the time of presentation, there was evidence of very active alopecia areata affecting more than $80 \%$ of her scalp hairs with sparing of non-pigmented hairs (Figs. la and 1b). In dermoscopy, she had a multiples short vellus and curly hairs. She was treated with a 6-month course of oral prednisolone and methotrexate and extensive hair regrowth occurred. The new hairs were non-pigmented (Figs. 2a and 2b). As a result, the patient's hair color is now white, with a normal hair density. This response has been sustained for 4 months

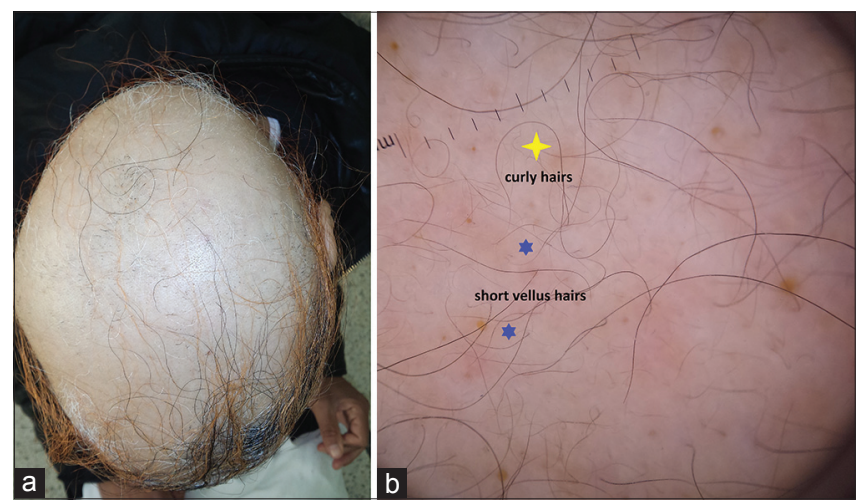

Figure 1: (a-b) Diffuse alopecia areata of the scalp. Dermoscopy: short vellus and curly hairs (before treatment).
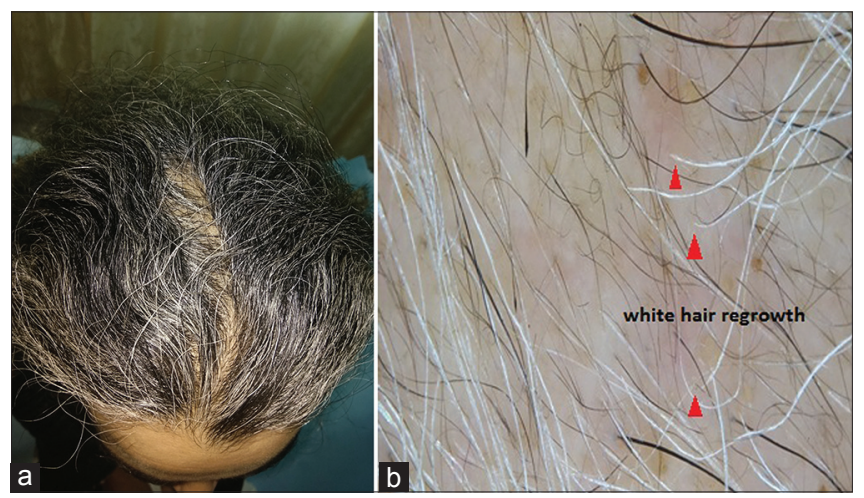

Figure 2: (a-b) Whitespread non pigmented hair regrowth.Dermoscopy: white hair regrowth (after treatment).

after cessation of treatment. Of note, there was no concurrent vitiligo on the scalp.

\section{CONSENT}

The examination of the patient was conducted according to the Declaration of Helsinki principles.

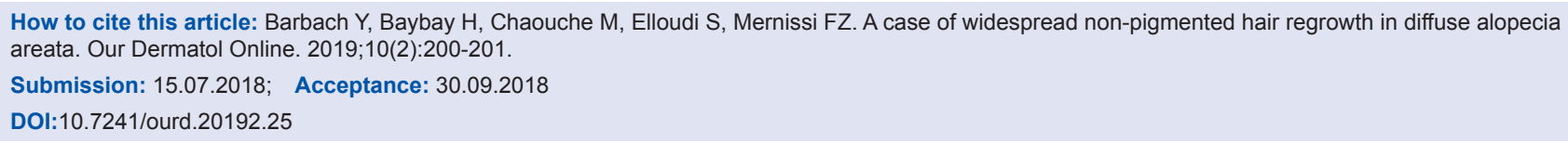


www.odermatol.com

\section{REFERENCES}

1. Nahm M, Navarini AA, Kelly EW. Canities Subita: A reappraisal of evidence based on 196 case reports published in the medical literature. Int J Trichology. 2013;5:63-8.

2. Dinh QQ, Chong AH. A case of widespread non-pigmented hair regrowth in diffuse alopecia areata. Australas J Dermatol. 2007;48:221-3.

3. Jalalat SZ, Kelsoe JR, Cohen PR. Alopecia areata with white hair regrowth: case report and review of poliosis. Dermatol Online J.
2014;20: pii: 13030/qt1xk5b26v

4. Navarini A, Nobbe A, Marie Antoinette Syndrome. Arch Dermatol. 2009;145: 656.

Copyright by Younes Barbach, et al. This is an open-access article distributed under the terms of the Creative Commons Attribution License, which permits unrestricted use, distribution, and reproduction in any medium, provided the original author and source are credited.

Source of Support: Nil, Conflict of Interest: None declared. 